\title{
Perioperative implications of sodium-glucose cotransporter-2 inhibitors: a case series of euglycemic diabetic ketoacidosis in three patients after cardiac surgery Implications périopératoires des inhibiteurs du cotransporteur sodium-glucose de type 2 : une série de cas d'acidocétose diabétique euglycémique chez trois patients suite à une chirurgie cardiaque
}

\author{
Aaron Lau, MD $\odot$ Simon Bruce, MD, FRCPC - Erica Wang, PharmD • \\ Ron Ree, MD, FRCPC · Kevin Rondi, MD, FRCPC • \\ Anthony Chau, MD, MMSc, FRCPC \\ Received: 14 July 2017/Revised: 18 August 2017/Accepted: 21 August 2017 / Published online: 22 November 2017 \\ (C) Canadian Anesthesiologists' Society 2017
}

\begin{abstract}
Purpose Sodium-glucose cotransporter-2 inhibitors (SGLT2i) comprise the newest class of oral hypoglycemic agents approved for treating type II diabetes mellitus (DMII). Their use, however, has been associated with the rare development of euglycemic diabetic ketoacidosis (euDKA). We present three cases of euDKA that occurred following elective coronary artery bypass grafting surgery. The role of the anesthesiologist in the prevention, diagnosis, and management of this complication is also discussed.

Clinical features Three patients receiving chronic SGLT2i therapy for DM-II (discontinued one to two days preoperatively) underwent cardiac surgery. On the first
\end{abstract}

This article is accompanied by an editorial. Please see Can J Anesth 2018; 65: this issue.

A. Lau, MD $(\bowtie) \cdot$ S. Bruce, MD, FRCPC $\cdot$ R. Ree, MD,

FRCPC $\cdot$ K. Rondi, MD, FRCPC .

A. Chau, MD, MMSc, FRCPC

Department of Anesthesiology, Pharmacology \& Therapeutics,

University of British Columbia, Vancouver, BC, Canada

e-mail: aaron.lau@medportal.ca

S. Bruce, MD, FRCPC $\cdot$ R. Ree, MD, FRCPC $\cdot$ K. Rondi, MD, FRCPC - A. Chau, MD, MMSc, FRCPC

Department of Anesthesiology, St. Paul's Hospital, Vancouver, BC, Canada

E. Wang, PharmD

Department of Pharmacy, Faculty of Pharmaceutical Sciences, St. Paul's Hospital, University of British Columbia, Vancouver, BC, Canada postoperative day, each exhibited nausea, vomiting, and tachypnea. Although these nonspecific postoperative findings are common, our patients also exhibited anion gap metabolic acidosis $(p H<7.3$, anion gap $>12$ $\left.\mathrm{mmol} \cdot \mathrm{L}^{-1}\right)$ with lower than anticipated serum glucose levels of $<14 \mathrm{mmol} \cdot \mathrm{L}^{-1}$. Serum and urine ketone analyses confirmed a diagnosis of euDKA. After insulin and dextrose infusions were initiated, rapid resolution of the metabolic abnormalities occured.

Conclusions Anesthesiologists should recognize that patients receiving SGLT2i preoperatively are at risk of developing euDKA. Hence, based on the pharmacokinetics of SGLT2i, discontinuing the medication at least two days prior to surgery should minimize the risk. Diagnosing euDKA is challenging and often delayed because of its nonspecific signs and symptoms. When suspected, serum and urine ketones should be monitored to reduce the time to diagnosis and treatment.
Résumé
Objectif Les inhibiteurs du cotransporteur sodium- glucose de type 2 (SGLT2i) englobent la classe la plus récente d'agents hypoglycémiques oraux approuvés pour le traitement du diabète de type II. Leur utilisation a toutefois été associée à l'apparition rare d'une acidocétose diabétique euglycémique. Nous présentons trois cas d'acidocétose diabétique euglycémique survenus à la suite d'une chirurgie de pontage aortocoronarien. Le rôle de l'anesthésiologiste dans la prévention, le diagnostic et 
la prise en charge de cette complication est également discuté.

Éléments cliniques Trois patients recevant une thérapie de SGLT2i pour le traitement de leur diabète de type II (interrompue un à deux jours avant leur opération) ont subi une chirurgie cardiaque. Au premier jour postopératoire, les trois patients ont souffert de nausées, de vomissements et de tachypnée. Bien que ces résultats postopératoires non spécifiques soient courants, nos patients ont également souffert d'une acidose métabolique à trou anionique $(\mathrm{pH}<$ 7.3, trou anionique $\left.>12 \mathrm{mmol} \cdot \mathrm{L}^{-1}\right)$ et des taux de glycémie sérique plus bas qu'anticipés à $<14 \mathrm{mmol} \cdot \mathrm{L}^{-1}$. Les analyses cétoniques sériques et dans l'urine ont confirmé le diagnostic d'acidocétose diabétique euglycémique. Suite à l'amorce de perfusions d'insuline et de dextrose, les anomalies métaboliques se sont rapidement résolues.

Conclusion Les anesthésiologistes devraient être sensibilisés au fait que les patients recevant des SGLT2i en période préopératoire courent un risque d'acidocétose diabétique euglycémique. Par conséquent, si l'on se fonde sur la pharmacocinétique des SGLT2i, l'interruption du traitement au moins deux jours avant la chirurgie devrait minimiser le risque. Le diagnostic de l'acidocétose diabétique euglycémique est difficile à poser et souvent retardé en raison de ses signes et symptômes non spécifiques. Lorsqu'elle est suspectée, les cétones sériques et dans l'urine devraient être mesurées afin de réduire le délai jusqu'au diagnostic et au traitement.

Sodium-glucose cotransporter-2 inhibitors (SGLT2i) comprise a novel class of medications that lower plasma glucose levels by enhancing glucosuria and other non-renal mechanisms. ${ }^{1}$ After an SGLT2i undergoes extensive glucuronidation, the resulting inactive metabolites are eliminated via renal and fecal routes. ${ }^{2}$ Since 2013 , three SGLT2i drugs (canagliflozin, dapagliflozin, empagliflozin) have been approved in Canada for treating type II diabetes mellitus (DM-II). The 2016 Canadian Diabetes Association guidelines recommend SGLT2i as second-line agents (after metformin and insulin) to improve cardiovascular outcomes. ${ }^{1,3}$ Rising rates of SGLT2i use have coincided with increased reports of ketoacidosis, leading the US Food and Drug Administration and Health Canada to publish safety advisories in May $2015^{4}$ and $2016^{1}$, respectively. Although the Canadian cases of ketoacidosis have involved only canagliflozin, ${ }^{1}$ evidence suggests that SGLT2iassociated ketoacidosis is a class effect, with a reported $0.1 \%$ event rate in SGLT2i clinical trials involving DM-II patients. $^{5}$
Diabetic ketoacidosis (DKA) typically occurs in type I diabetic patients and presents with nonspecific symptoms (e.g., tachypnea, nausea, vomiting, abdominal pain), anion gap metabolic acidosis (AGMA), with $\mathrm{pH}<7.3$, anion gap $>12 \mathrm{mmol} \cdot \mathrm{L}^{-1}$, and hyperglycemia (serum glucose $\geq 14$ mmol $\left.\cdot \mathrm{L}^{-1}\right){ }^{6}$ In contrast, patients with SGLT2i-associated ketoacidosis present with AGMA but lower-thananticipated serum glucose levels of $<14 \mathrm{mmol} \cdot \mathrm{L}^{-1}$ (i.e., euglycemic DKA [euDKA]). ${ }^{6}$ Given its low incidence and nonspecific presentation, early diagnosis of euDKA can be challenging. Delayed diagnosis and suboptimal treatment of euDKA may result in severe clinical complications mirroring those of DKA, with confusion, progressive metabolic decompensation, and hypovolemic shock. ${ }^{7}$

In the perioperative setting, patients on SGLT2 $i$ are particularly at increased risk of developing euDKA in the presence of precipitating factors such as prolonged fasting, dehydration, and/or surgical stress due to disrupted glucose homeostatic mechanisms. ${ }^{6}$

We present a case series of three patients (all of whom provided written consent for this report) with euDKA who were taking an SGLT2i (empagliflozin) and who underwent elective coronary artery bypass grafting (CABG) surgery. We report herein their perioperative management and the overall need for early recognition and management of euDKA.

\section{Case presentations}

\section{Case 1}

A 54-year-old, $97 \mathrm{~kg}$ man with a history of DM-II treated with NPH insulin and empagliflozin $25 \mathrm{mg}$ daily was scheduled for elective CABG. Empagliflozin was withheld one day prior to surgery (last dose was $\sim 48$ hours prior to surgery), and he fasted from $8 \mathrm{pm}$ the previous evening. Initial arterial blood gas (ABG) analysis prior to institution of cardiopulmonary bypass (CPB) demonstrated nonAGMA with normoglycemia (Table). During the operation, he was on an insulin infusion of $5 \mathrm{U} \cdot \mathrm{hr}^{-1}$ until arrival in the cardiac surgery intensive care unit (CSICU), where the infusion was discontinued within three hours. In preparation for extubation that evening, laboratory tests showed mixed respiratory acidosis and AGMA of 15 $\mathrm{mmol} \cdot \mathrm{L}^{-1} \quad\left(\mathrm{pH}\right.$ 7.28, $\mathrm{PCO}_{2} 40 \mathrm{mmHg}, \quad \mathrm{HCO}_{3}^{-} 18$ $\mathrm{mmol} \cdot \mathrm{L}^{-1}$, base excess $[\mathrm{BE}]-8 \mathrm{mmol} \cdot \mathrm{L}^{-1}$, lactate 1.1 $\mathrm{mmol} \cdot \mathrm{L}^{-1}$, glucose $12.0 \mathrm{mmol} \cdot \mathrm{L}^{-1}$ ). The AGMA was attributed to a combination of propofol sedation and serum lactate. Later that evening, the patient had one episode of nausea and one of emesis, which resolved with administration of intravenous ondansetron $4 \mathrm{mg}$ and oral dimenhydrinate $25 \mathrm{mg}$. Overnight, the patient developed 
Table Case information summary

\begin{tabular}{|c|c|c|c|}
\hline Parameter & Case 1 & Case 2 & Case 3 \\
\hline Age and sex & $54 \mathrm{yr}$ old, male & 58 yr old, male & $54 \mathrm{yr}$ old, male \\
\hline Alc $(\%)$ & 9.2 & 7.6 & 6.4 \\
\hline BMI $\left(\mathrm{kg} \cdot \mathrm{m}^{-2}\right)$ & 30.6 & 23.2 & 23.7 \\
\hline Preoperative creatinine $\left(\mu \mathrm{mol} \cdot \mathrm{L}^{-1}\right)$ & 127 & 59 & 57 \\
\hline Preoperative eGFR $\left(\mathrm{mL} \cdot \mathrm{min}^{-1}\right)$ & 55 & 106 & 110 \\
\hline Albumin $\left(\mathrm{g} \cdot \mathrm{L}^{-1}\right)$ & 36 & 42 & 44 \\
\hline SGLT2i & Empagliflozin $25 \mathrm{mg}$ po daily & Empagliflozin $25 \mathrm{mg}$ po daily & Empagliflozin $25 \mathrm{mg}$ po daily \\
\hline Last SGLT2i dose prior to surgery & $\sim 48$ hours & $\sim 28$ hours & $\sim 20$ hours \\
\hline Other diabetic medications & $\begin{array}{l}\mathrm{NPH} \text { insulin } 13 \text { units } s c \mathrm{q} \text { am } \\
\quad \text { and } 15 \text { units } s c \mathrm{q} \mathrm{pm}\end{array}$ & $\begin{array}{l}\text { Metformin } 500 \mathrm{mg} \text { po bid } \\
\text { Gliclazide } 60 \mathrm{mg} \mathrm{q} \text { am and } 30 \mathrm{mg} \mathrm{q} \text { hs }\end{array}$ & Metformin $1000 \mathrm{mg}$ po bid \\
\hline \multicolumn{4}{|l|}{ Preoperative nро duration } \\
\hline - Last meal & POD -1@2000 hr & POD -1@2100hr & POD -1@2000hr \\
\hline - Last fluid & POD -1@ 2000 hr & POD $0 @ 0700$ hr - water & POD -1@2000hr \\
\hline Operation & CABG & CABG & OPCAB \\
\hline Pre-CPB/OPCAB ABG & @ 1010 hr & @ 1306 hr & @ 1438 hr \\
\hline$-\mathrm{pH}$ & 7.30 & 7.39 & 7.34 \\
\hline - $\mathrm{PCO}_{2}(\mathrm{mmHg})$ & 42 & 38 & 47 \\
\hline$-\mathrm{HCO}_{3}^{-}\left(\mathrm{mmol} \cdot \mathrm{L}^{-1}\right)$ & 21 & 22.9 & 25 \\
\hline - Base excess $\left(\mathrm{mmol} \cdot \mathrm{L}^{-1}\right)$ & -5.0 & 1.8 & -0.7 \\
\hline - Serum glucose $\left(\mathrm{mmol} \cdot \mathrm{L}^{-1}\right)$ & 5.7 & 4.9 & 7.1 \\
\hline - Lactate $\left(\mathrm{mmol} \cdot \mathrm{L}^{-1}\right)$ & 0.4 & 0.6 & 0.8 \\
\hline - Glucose $\left(\mathrm{mmol} \cdot \mathrm{L}^{-1}\right)$ & 5.7 & 4.9 & 7.1 \\
\hline \multicolumn{4}{|l|}{ Symptoms of DKA } \\
\hline - Nausea & Nausea & Nil & Nausea \\
\hline - Vomiting & Vomiting & Nil & Nil \\
\hline - Abdominal pain & Nil & Nil & Nil \\
\hline - Altered mental status & Nil & Nil & Nil \\
\hline - Altered respiratory pattern & Tachypnea & Tachypnea & Tachypnea \\
\hline Signs of DKA (once suspected) & POD 1@0508 hr & POD $1 @ 0455$ hr & POD0@0507 hr \\
\hline$-\mathrm{pH}$ & 7.24 & 7.30 & 7.33 \\
\hline$-\mathrm{PCO}_{2}(\mathrm{mmHg})$ & 32 & 36 & 32 \\
\hline$-\mathrm{HCO}_{3}^{-}\left(\mathrm{mmol} \cdot \mathrm{L}^{-1}\right)$ & 14 & 17 & 16 \\
\hline - Base excess $\left(\mathrm{mmol} \cdot \mathrm{L}^{-1}\right)$ & -12 & -8 & -8 \\
\hline - Anion gap $\left(\mathrm{mmol} \cdot \mathrm{L}^{-1}\right)$ & 15 & 14 & 12 \\
\hline - Serum glucose $\left(\mathrm{mmol} \cdot \mathrm{L}^{-1}\right)$ & 12 & 6.2 & 9.6 \\
\hline - Serum $\beta$-HB $\left(\mathrm{mmol} \cdot \mathrm{L}^{-1}\right)$ & 5.26 & 4.63 & 0.98 \\
\hline - Serum ketones & Not performed & Moderate & Not performed \\
\hline - Serum lactate $\left(\mathrm{mmol} \cdot \mathrm{L}^{-1}\right)$ & 1.1 & 1.4 & 2.8 \\
\hline - Potassium $\left(\mathrm{mmol} \cdot \mathrm{L}^{-1}\right)$ & 5.4 & 4.2 & 4.4 \\
\hline POD 1 creatinine $\left(\mu \mathrm{mol} \cdot \mathrm{L}^{-1}\right)$ & 156 & 64 & 64 \\
\hline POD 1 eGFR $\left(\mathrm{mL} \cdot \mathrm{min}^{-1}\right)$ & 43 & 103 & 105 \\
\hline Urinalysis & Not performed & POD $1 @ 1040$ hr & POD1@1006 hr \\
\hline - Urine glucose $\left(\mathrm{mmol} \cdot \mathrm{L}^{-1}\right)$ & Not performed & $>55$ & $>55$ \\
\hline - Urine ketones $\left(\mathrm{mmol} \cdot \mathrm{L}^{-1}\right)$ & Not performed & $>7.8$ & 3.9 \\
\hline - Urine output - first 24 hours in CSICU & 1880 & 3280 & 2940 \\
\hline PONV prophylaxis & Nil & Nil & Dexamethasone $6 \mathrm{mg}$ \\
\hline
\end{tabular}

$\overline{\mathrm{ABG}}=$ arterial blood gas; $\beta$ - $\mathrm{HB}=\beta$-hydroxybutyrate $\left(\right.$ normal $\left.<0.31 \mathrm{mmol} \cdot \mathrm{L}^{-1}\right) ;$ bid $=$ twice daily; $\mathrm{BMI}=$ body mass index; $\mathrm{CABG}=$ coronary artery bypass graft CPB $=$ cardiopulmonary bypass; CSICU $=$ cardiac surgical intensive care unit; DKA $=$ diabetic ketoacidosis; $n$ po $=$ nil per os; eGFR $=$ estimated glomerular filtration rate; $\mathrm{OPCAB}=$ off-pump coronary artery bypass; $\mathrm{POD}=$ postoperative day $(-1=$ day prior to surgery; $0=$ day of surgery; $1=$ day after surgery); PONV = postoperative nausea and vomiting; $s c=$ subcutaneous; SGLT2i = sodium-glucose transporter 2 inhibitor 
tachypnea (up to 27 respirations $\cdot \mathrm{min}^{-1}$ ), which resolved with analgesic administration. Serial $\mathrm{ABG}$ results revealed downward trending $\mathrm{pH}$ and $\mathrm{HCO}_{3}^{-}$levels. Urinary output of $1880 \mathrm{~mL}$ was noted within the first 24-hr period. Laboratory investigations on postoperative day (POD) 1 demonstrated AGMA with normoglycemia (Table). Further workup for AGMA revealed elevated serum $\beta$ hydroxybutyrate $(\beta-\mathrm{HB})$ of $5.26 \mathrm{mmol} \cdot \mathrm{L}^{-1}$ (normal $<$ $0.31 \mathrm{mmol} \cdot \mathrm{L}^{-1}$ ), and DKA was diagnosed. In consultation with the endocrinology service, an insulin infusion was started at $2 \mathrm{U} \cdot \mathrm{hr}^{-1}$ along with administration of $5 \%$ dextrose in water (D5W) at $5 \mathrm{~mL} \cdot \mathrm{hr}^{-1}$ and $100 \mathrm{mmol}$ of intravenous sodium bicarbonate. Within four hours, the anion gap was closed $\left(\mathrm{pH} 7.14, \mathrm{PCO}_{2} 38 \mathrm{mmHg}, \mathrm{HCO}_{3}^{-} 20\right.$ $\mathrm{mmol} \cdot \mathrm{L}^{-1}, \mathrm{BE}-4 \mathrm{mmol} \cdot \mathrm{L}^{-1}$, anion gap $9 \mathrm{mmol} \cdot \mathrm{L}^{-1}$, normoglycemia). The patient remained asymptomatic throughout the duration of treatment for euDKA and was restarted on NPH insulin 13 units subcutaneously twice daily with the insulin sliding-scale on POD 2 showing no signs of euDKA. He was discharged home on metformin (instead of empagliflozin) and NPH insulin with routine outpatient endocrinology follow-up.

\section{Case 2}

A 58-year-old, $71 \mathrm{~kg}$ man with a history DM-II was on metformin, gliclazide, and empagliflozin $25 \mathrm{mg}$ daily. All three medications were withheld one day prior to his afternoon elective CABG (last dose of empagliflozin was $\sim 28$ hours prior to surgery), and he had fasted from $9 \mathrm{pm}$ the evening prior to the operation. The initial ABG analysis prior to instituting CPB was normal. The operation was uneventful. After arriving in the CSICU, the patient was extubated during the early evening without nausea or emesis. On the morning of POD 1, there was gradual onset of tachypnea (up to 26 respirations $\cdot \mathrm{min}^{-1}$ ), which resolved with analgesics. Urinary output of $3280 \mathrm{~mL}$ was noted within the first 24-hour period. Laboratory investigations on POD 1 showed AGMA with normoglycemia. While investigating the AGMA etiology, the clinical team (with prior experience managing the first case) identified SGLT2i as a possible precipitant. Standard DKA blood work revealed moderate serum ketones, an elevated serum $\beta$ HB level of $4.63 \mathrm{mmol} \cdot \mathrm{L}^{-1}$, urine glucose $>55 \mathrm{mmol} \cdot \mathrm{L}^{-1}$, and urine ketones $>7.8 \mathrm{mmol} \cdot \mathrm{L}^{-1}$. The patient was initially started on an insulin infusion of $3 \mathrm{U} \cdot \mathrm{hr}^{-1}$ with D5W. By early afternoon, the AGMA had resolved $(\mathrm{pH}$ 7.38, $\mathrm{PCO}_{2} 38 \mathrm{mmHg}, \mathrm{HCO}_{3}^{-} 22 \mathrm{mmol} \cdot \mathrm{L}^{-1}, \mathrm{BE}-2$ $\mathrm{mmol} \cdot \mathrm{L}^{-1}$, anion gap $6 \mathrm{mmol} \cdot \mathrm{L}^{-1}$, glucose $9.6 \mathrm{mmol} \cdot \mathrm{L}^{-1}$ ). On POD 2, laboratory investigations showed normalization of the metabolic abnormalities. Insulin infusion therapy was discontinued with no further ketotic abnormalities. The patient was transitioned back to metformin and gliclazide with sliding-scale insulin. Empagliflozin was not restarted. With no further ketotic abnormalities while in hospital, he was discharged without additional diabetic medication changes.

Case 3

A 54-year-old, $70 \mathrm{~kg}$ man with a history of DM-II on metformin and empagliflozin $25 \mathrm{mg}$ daily had both medications withheld (last dose of empagliflozin was $\sim 20$ hours prior to surgery) the evening prior to his afternoon elective off-pump CABG (OPCAB). The patient had fasted from $8 \mathrm{pm}$ the night before. The initial $A B G$ analysis, performed after anesthesia induction, showed mild respiratory acidosis. Surgery proceeded uneventfully, and the patient was extubated during the early evening without complications. Repeated doses of dimenhydrinate (total $100 \mathrm{mg} \mathrm{po}$ ) were administered for nausea without emesis during the first 24 hours. Gradual onset of tachypnea (up to 24 respirations $\cdot \mathrm{min}^{-1}$ ) was noted during the early morning of POD 1 but resolved with analgesics. Urinary output of $2940 \mathrm{~mL}$ was noted within the first 24hour period. Laboratory investigations on POD 1 revealed AGMA with normoglycemia. An investigative workup for AGMA showed an elevated serum $\beta$-HB level of 0.98 $\mathrm{mmol} \cdot \mathrm{L}^{-1}$, urine glucose $>55 \mathrm{mmol} \cdot \mathrm{L}^{-1}$, urine ketones $3.9 \mathrm{mmol} \cdot \mathrm{L}^{-1}$. Insulin infusion with $\mathrm{D} 5 \mathrm{~W}$ at $1 \mathrm{U} \cdot \mathrm{hr}^{-1}$ was initiated. By early afternoon, the anion gap had decreased to $5 \mathrm{mmol} \cdot \mathrm{L}^{-1}$ with the serum $\beta$-HB level at $<0.1$ $\mathrm{mmol} \cdot \mathrm{L}^{-1}$. Serum glucose remained at normoglycemic levels. Given the lack of clinical and serum markers for ongoing DKA, the insulin infusion was discontinued, and the patient was restarted on home-dose metformin with sliding-scale insulin (excluding empagliflozin). No further metabolic abnormalities were noted during the remainder of his hospital admission.

\section{Discussion}

In this case series, three patients on chronic empagliflozin therapy developed euDKA on POD 1 following elective CABG surgery despite discontinuation of empagliflozin 24-48 hours preoperatively. Recognizing the risks associated with the use of SGLT2i allows perioperative planning that renders the development of euDKA a detectable and preventable outcome. ${ }^{7}$

Sodium-glucose cotransporters are active glucose carriers that are predominantly expressed in the proximal tubule of the kidney and pancreatic alpha cells. ${ }^{8}$ In the kidneys, SGLT2i prevent reabsorption of filtered glucose, resulting in glucosuria, partial correction of hyperglycemia, and reduced glucotoxicity. In pancreatic alpha cells, 
SGLT2i alter glucose sensory mechanisms, which results in increased glucagon levels. ${ }^{7}$ Both sites of action create the mileu for ketogenesis (i.e., deficient insulin production from pancreatic beta cells with glucagon elevation promotes lipolysis and hepatic ketogenesis). SGLT2i may also decrease renal clearance of ketone bodies and enhance renal ketone reabsorption. ${ }^{6}$ Although SGLT2i-associated DKA and DKA have similar pathophysiological mechanisms, the respective euglycemic or hyperglycemic presentation is ultimately determined by the equilibrium of endogenous glucose production and renal glucose clearance. $^{6}$ Euglycemia predominates in SGLT2iassociated DKA because milder insulin deficiency reduces glucose overproduction, decreased insulin resistance promotes glucose uptake, and renal glucose clearance occurs at twice the typical rate observed in DKA. $^{7}$

In the perioperative setting, multiple factors further reduce the lowered insulin-to-glucagon ratio associated with SGLT2i, precipitating the development of euDKA. Preoperative factors include regimens which increase the risk of dehydration and fasting guidelines that limit carbohydrate intake. ${ }^{8}$ In response to major surgical stimuli, physiological release of counter-regulatory hormones (epinephrine, cortisol, inflammatory mediators) and acute insulin resistance stimulate gluconeogenesis, glycogenolysis, and ketogenesis.

Therefore, certain perioperative issues should be considered. First, it is recommended that SGLT2i administration be withheld until adequate hydration and normal diet resumes. ${ }^{6}$ Second, for major elective surgical procedures, SGLT2i should be discontinued three days preoperatively, with the last dose taken no less than 55-65 hours prior to the surgery (based on the average 11- to 13-hour half-life of SGLT2i). ${ }^{6}$ Third, for patients with DM-II on insulin therapy, as in case 1, reductions in the insulin dose may precipitate euDKA. ${ }^{6,8}$ As SGLT2i may mask true insulin requirements due to greater renal glucose excretion and reduced insulin secretion and utilization, it is recommended that overt discontinuation, or rapid reduction, of the insulin dose be avoided after major surgery. ${ }^{6}$

When SGLT2i are not adequately withheld preoperatively (e.g., for urgent/emergent surgical procedures), our case series demonstrated that the onset of euDKA can occur quite rapidly. In all three cases, signs of euDKA were noted within the first 24 hours postoperatively, evidenced by positive urine and serum ketone tests and postoperative urinary output greater than the expected $0.5-1.0 \mathrm{~mL} \cdot \mathrm{kg}^{-1} \cdot \mathrm{hr}^{-1}$ without the use of diuretics. This is likely due to inadequate SGLT2i clearance with residual glucosuria, the concurrent fasting status, and major surgical stress. Development of euDKA is noted consistently when SGLT2i are withheld only for the day prior to surgery. ${ }^{9-11}$

It is uncertain whether concomitant metformin use contributes to euDKA development, although evidence suggests that metformin is not associated with an increased risk of adverse outcomes in cardiac surgical patients. ${ }^{12}$ Moreover, analysis of case reports show no association between the medication regimen and euDKA risk. ${ }^{8}$ This lack of ketogenesis may reflect metformin's targeted tissue sensitization to insulin being counterbalanced by its inhibition of gluconeogenesis. The influence of $\mathrm{CPB}$, compared with OPCAB surgery, is also unknown, although $\mathrm{CPB}$ is known to be a major factor in triggering an inflammatory response, with increased stress hormone release. $^{13}$ Although DKA associated with CPB can occur, ${ }^{14}$ instances of euDKA with $\mathrm{CPB}$ have not been previously reported. The inflammatory response to $\mathrm{OPCAB}$ may be different but remains significant. ${ }^{15,16}$ The occurrence of euDKA in the presence of both CABG and OPCAB in our case series suggests that, in the presence of SGLT2i, any major surgery is a sufficient precipitating factor.

Although vigilance for detecting euDKA development is vital during the perioperative period, particularly given the predilection for ketosis when residual effects of SGLT2i remain, there are also specific diagnostic challenges. The nonspecific clinical symptoms associated with euDKA can initially be attributed to typical postoperative issues, including postoperative nausea and emesis, surgical site pain, or tachypnea secondary to splinting. Additionally, hyperglycemia-induced signs typical of DKA (e.g., polyuria) may not be present in euDKA patients or may be masked by perioperative hypovolemia. Finally, routine postoperative serum chemistry tests and glucose monitoring used to detect hyperglycermia in diabetic patients are not as reliable as serum/ urine ketone monitoring for diagnosing ketosis.

Given these considerations, opportunities for perioperative interventions exist. Optimization of analgesia and maintenance of euvolemia can help minimize further counter-regulatory hormone stimuli. Provision of intravenous dextrose with exogenous insulin to normalize the reduced insulin-to-glucagon ratio associated with SGLT2i may be required until patients can resume oral intake of carbohydrates and diabetic medications. Institutional protocols regarding postoperative timing and frequency of ketone monitoring, specifically blood ketone $\beta$-HB (the predominant ketone body in DKA), should be developed for patients recently on an SGLT2i. ${ }^{6}$ If euDKA occurs, its management should parallel that of DKA, with volume resuscitation with crystalloids, correction of electrolyte abnormalities, and insulin infusion with dextrose-containing intravenous solutions to limit further lipolysis and ketogenesis. ${ }^{7,9-11}$ 
In our case series, the oral diabetic agents (except SGLT2i) that were taken preoperatively were restarted while the patient was still hospitalized, a practice that resulted in no subsequent readmissions for euDKA. Nonetheless, development of euDKA remains a possibility for patients transitioning back to their previous SGLT2i regimen. ${ }^{10}$ If the SGLT2i is to be reinitiated while still in the hospital, the timing should be based on the clinician's judgement and only when precipitating factors have resolved. The patient should undergo appropriate follow-up and education by the prescribing clinician regarding the signs and symptoms of euDKA that would warrant further medical attention.

These cases prompted changes in our own institutional perioperative protocol. Standard preoperative cardiac surgery orders have been modified to specify withholding SGLT2 $i$ for two days prior to surgery. Because the SGLT2i is typically taken in the morning, withholding two days prior to surgery (i.e., skipping two morning doses) would result in the last dose being taken approximately 72 hours prior to surgery. This timing is in keeping with the current recommendations that balance the pharmacokinetic properties of SGLT2i and the risk of perioperative hyperglycemia. ${ }^{6}$ The staff in our preadmission clinic has been educated on the role of SGLT2i in diabetes management and the need to coordinate a perioperative glucose control plan. In the postanesthetic recovery unit and cardiac surgery ICU, anesthesiologists, intensivists, and nursing providers have been educated to recognize and assess any potential signs and symptoms of euDKA. Without a database available from which to retrieve information regarding patients taking SGLT2i, a quality improvement project is underway to assess the scope of SGLT2i use with euDKA development associated with both cardiac and noncardiac surgeries. A perioperative ketone monitoring protocol for patients recently on SGLT2 $i$ is also in development.

Disclosures None of the authors has any competing financial interests related to this study.

Consent Written consent has been obtained from all three patients at St. Paul's Hospital, Vancouver, BC, for publication of this case series, which has been attached at the time of submission.

Author contributions Aaron Lau contributed substantially to all aspects of this manuscript, including study conception and design, data acquisition, data analysis and interpretation, and drafting the article. Simon Bruce and Anthony Chau contributed substantially to aspects of this manuscript, including study conception and design, data analysis and interpretation, and critical review of the article. Erica Wang contributed substantially to aspects of this manuscript, including data acquisition, data analysis and interpretation, and critical review of the article. Ron Ree and Kevin Rondi contributed substantially to aspects of this manuscript, including data analysis and interpretation and critical review of the article.
Editorial responsibility This submission was handled by Dr. Hilary P. Grocott, Editor-in-Chief, Canadian Journal of Anesthesia.

Funding Nil.

\section{References}

1. Health Canada. Summary Safety Review - SGLT2 inhibitors (canagliflozin, dapagliflozin, empagliflozin) - Assessing the risk of the body producing high levels of acids in the blood (diabetic ketoacidosis). Available from URL: https://www.canada.ca/en/ health-canada/services/drugs-health-products/medeffect-canada/ safety-reviews/summary-safety-review-sglt2-inhibitors-canagliflozindapagliflozin-empagliflozin.html (accessed August 2017).

2. Scheen AJ. Pharmacodynamics, efficacy and safety of sodiumglucose co-transporter type 2 (SGLT2) inhibitors for the treatment of type 2 diabetes mellitus. Drugs 2015; 75: 33-59.

3. Anonymous. Pharmacologic management of type 2 diabetes: 2016 interim update. Can J Diabetes 2016; 40: 193-5.

4. U.S. Food \& Drug Administration. FDA Drug Safety Communication: FDA warns that SGLT2 inhibitors for diabetes may result in a serious condition of too much acid in the blood. Available from URL: https://www.fda.gov/downloads/ drugs/drugsafety/ucm446954.pdf (accessed August 2017).

5. Tang H, Li D, Wang T, Zhai S, Song Y. Effect of sodium-glucose cotransporter 2 inhibitors on diabetic ketoacidosis among patients with type 2 diabetes: a meta-analysis of randomized controlled trials. Diabetes Care 2016; 39: e123-4.

6. Goldenberg RM, Berard LD, Cheng AY, et al. SGLT2 inhibitorassociated diabetic ketoacidosis: Clinical review and recommendations for prevention and diagnosis. Clin Ther 2016; 38(2654-64): e1.

7. Rosenstock J, Ferrannini E. Euglycemic diabetic ketoacidosis: a predictable, detectable, and preventable safety concern with SGLT2 inhibitors. Diabetes Care 2015; 38: 1638-42.

8. Burke KR, Schumacher CA, Harpe SE. SGLT2 inhibitors: a systematic review of diabetic ketoacidosis and related risk factors in the primary literature. Pharmacotherapy 2017; 37: 187-94.

9. Bonanni FB, Fei P, Fitzpatrick LL. Normoglycemic ketoacidosis in a postoperative gastric bypass patient taking canagliflozin. Surg Obes Relat Dis 2016; 12: e11-2.

10. Peters AL, Buschur EO, Buse JB, Cohan P, Diner JC, Hirsch LB. Euglycemic diabetic ketoacidosis: a potential complication of treatment with sodium-glucose cotransporter 2 inhibition. Diabetes Care 2015; 38: 1687-93.

11. Wood T, Pang AJ, Hallet J, Greig P. Euglycaemic ketoacidosis in a postoperative Whipple patient using canagliflozin. BMJ Case Rep 2016. https://doi.org/10.1136/bcr-2016-216607.

12. Duncan AI, Koch CG, Xu M, et al. Recent metformin ingestion does not increase in-hospital morbidity or mortality after cardiac surgery. Anesth Analg 2006; 104: 42-50.

13. Raja $S G$. Pump or no pump for coronary artery bypass. Tex Heart Inst J 2005; 32: 489-501.

14. Peterson C, Fox JA, Devallis P, Rizzo R, Mizuguchi KA. Starvation in the midst of cardiopulmonary bypass: diabetic ketoacidosis during cardiac surgery. J Cardiothorac Vasc Anesth 2012; 26: 910-6.

15. Wang $Y$, Shi $X, D u R$, Chen $Y$, Zhang $Q$. Off-pump versus onpump coronary artery bypass grafting in patients with diabetes: a meta-analysis. Acta Diabetol 2017; 54: 283-92.

16. Sondekoppam RV, Arellano R, Ganapathy $S$, Cheng D. Pain and inflammatory response following off-pump coronary artery bypass grafting. Curr Opin Anaesthesiol 2014; 27: 106-15. 